\title{
CORRIGENDUM
}

\section{Targeting gene expression to cones with human cone opsin promoters in recombinant AAV}

AM Komáromy, JJ Alexander, AE Cooper, VA Chiodo, GM Acland, WW Hauswirth and GD Aguirre

Gene Therapy (2011) 18, 1179; doi:10.1038/gt.2011.156

Correction to: Gene Therapy (2008) 15, 1049-1055; doi:10.1038/ The authors would like to apologise for this error. gt.2008.32; published online 13 March 2008

Since the online publication of this paper the authors have noticed that they omitted grant number EY-17549 from the National Institutes of Health in the Acknowledgements section. 